\title{
Efectos de la transformación digital en la empresa publicitaria de la Comunidad Valenciana
}

\author{
Paloma Sanz-Marcos \\ Profesora del Departamento de Comunicación Audiovisual \\ y Publicidad de la Universidad de Sevilla.
}

\section{Referencia de este artículo}

Sanz-Marcos, Paloma (2019). Efectos de la transformación digital en la empresa publicitaria de la Comunidad Valenciana. En: adComunica. Revista Científica de Estrategias, Tendencias e Innovación en Comunicación, (18). 309-312. DOI: http:// dx.doi.org/10.6035/2174-0992.2019.18.17

GONZÁLEZ OÑATE, Cristina (coord.) (2019).

El negocio publicitario en la sociedad digital de la Comunidad Valenciana.

Barcelona: UOC.

Esta obra se erige como una referencia imprescindible para conocer a fondo el ámbito de la publicidad en la Comunidad Valenciana. No obstante, lejos de presentarse como un manual de aplicación exclusivamente local, aporta una visión novedosa de los retos y cambios que ha sufrido este sector de manera global a consecuencia del desarrollo de los medios digitales. Como resultado del proyecto de investigación titulado El negocio publicitario en la sociedad digital: estructura de agencia, perfiles profesionales y nuevas tendencias creativas (Plan de Promoción Universitat Jaume I P1-1B2015-27), la coordinadora de este texto, experta en las nuevas tendencias de comunicación, realiza junto con el resto de autores una novedosa aportación acerca de las oportunidades y desafíos que supone la consolidación de las herramientas del medio online a fin de aplicar estos resultados a la realidad empresarial. 
Centrado en introducir el fenómeno de las nuevas tecnologías de la información y la comunicación, el capítulo inicial enmarca las bases y procedimientos que se han llevado a cabo para desarrollar esta investigación. En concreto, se detalla todo el proceso de trabajo; desde los participantes y herramientas empleadas, hasta las conclusiones más interesantes como resultado de la investigación. Con objeto de hacer un repaso integral de la agencia de publicidad, los capítulos siguientes, muestran cómo las estructuras de trabajo se han visto modificadas por el avance de la era digital. Así, el segundo capítulo plantea continuar con una investigación anterior cuyo objetivo se propone conocer la evolución y características de las agencias de publicidad de la Comunidad Valenciana. Se trata de un apartado interesante en tanto que explora de manera detallada no sólo las diversas tipologías de las agencias y cómo han ido cambiando, al mismo tiempo, ofrece un estudio minucioso de la estructura interna organizativa de las mismas. En este sentido, se subraya cómo internet ha renovado el modo en el que se entienden ciertos aspectos de la comunicación como el receptor, el contexto o el propio consumidor, resultando en una gestión de la publicidad que ha de ser considerada desde un enfoque sistémico e integrador. Por su parte, el capítulo tercero se centra en los perfiles profesionales del sector desde una profunda reflexión en torno a los cambios que ha supuesto la digitalización de los formatos publicitarios. No sólo se describen las consecuencias y nuevos retos de estos perfiles, asimismo, se hace un amplio repaso de las funciones y tareas a desempeñar dentro de los distintos departamentos tanto de nueva creación, como en el caso de las agencias tradicionales. Este capítulo se cierra con una serie de aptitudes reclamadas a modo de recomendaciones que han surgido por parte de los especialistas que han participado en la investigación. En su objetivo de presentar la realidad profesional del sector, el siguiente capítulo estudia la relación entre los profesionales de la publicidad y los clientes. En cuanto en la figura del anunciante, atiende de forma pormenorizada a aquellas cuestiones más cotidianas que se precisan considerar para mantener el equilibrio entre el mundo empresarial y la realidad digital, y garantizar así unos servicios equilibrados. En este caso, se advierten cuestiones como las relaciones corporativas, los servicios más demandados por las pymes valencianas o cómo la remuneración ha de ser replanteada en el entorno digital. Para finalizar, se propone una catalogación de los distintos servicios que ofrecen las agencias de publicidad en esta comunidad. La obra se cierra con un quinto capítulo dedicado al futuro de las agencias publicitarias. A través de las opiniones recogidas por parte de los profesionales entrevistados, se valora el rumbo y retos que dibujarán el futuro del sector de entre los que se destacan unas relaciones de trabajo más horizontales, la reducción de los equipos de trabajo o la búsqueda de nichos de mercado innovadores. En cuanto al carácter formal de esta obra, se trata de un texto que, a través de su estilo y presentación de los contenidos, se configura como un manual de gran utilidad que abarca las perspectivas del sector desde un punto de vista científico. Algo que resulta necesario dado que apenas existen referencias que traten las realidades profesionales desde una metodología rigurosa. 
Sin duda, nos encontramos ante un texto que ha de considerarse como un gran apoyo y servicio al mundo profesional desde el impulso académico que si bien, otras obras recientes como Empresa publicitaria de los autores Francisco J. Caro y Jorge David Fernández (Advook, 2016), o La transformación digital de la agencia de publicidad (Universidad de Navarra, 2017) del autor Jürg Kaufmann Argueta, han destacado, ofrece una novedosa aportación al incorporar una visión integradora de las consecuencias a nivel creativo y de gestión que sufren las agencias de publicidad como consecuencia de la evolución digital.

En definitiva, y a pesar de que este volumen ofrece una perspectiva práctica y cercana de la realidad y funcionamiento del caso aislado concreto del sector publicitario de la Comunidad Valenciana, podría aplicarse a otras localidades con objeto de servir de gran utilidad para la formación de los estudiantes y futuros profesionales del sector. 
